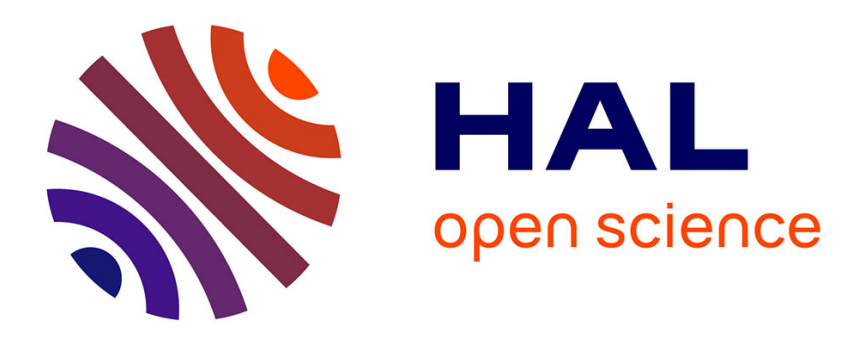

\title{
I-V characteristics of polycrystalline silicon resistors
}

\author{
G. Baccarani, M. Impronta, B. Riccò, P. Ferla
}

\section{To cite this version:}

G. Baccarani, M. Impronta, B. Riccò, P. Ferla. I-V characteristics of polycrystalline silicon resistors. Revue de Physique Appliquée, 1978, 13 (12), pp.777-782. 10.1051/rphysap:019780013012077700 . jpa-00244545

\section{HAL Id: jpa-00244545 https://hal.science/jpa-00244545}

Submitted on 1 Jan 1978

HAL is a multi-disciplinary open access archive for the deposit and dissemination of scientific research documents, whether they are published or not. The documents may come from teaching and research institutions in France or abroad, or from public or private research centers.
L'archive ouverte pluridisciplinaire HAL, est destinée au dépôt et à la diffusion de documents scientifiques de niveau recherche, publiés ou non, émanant des établissements d'enseignement et de recherche français ou étrangers, des laboratoires publics ou privés. 


\title{
I-V CHARACTERISTICS OF POLYCRYSTALline SILICON RESISTORS (*)
}

\author{
G. BACCARANI, M. IMPRONTA, B. RICCÒ \\ Istituto di Elettronica, Università di Bologna, Bologna, Italy \\ and \\ P. FERLA
}

SGS-Ates, Agrate Brianza, Milano, Italy

\begin{abstract}
Résumé. - On examine ici les propriétés des résistors en silicium polycristallin. La méthode employée est basée sur un mécanisme de transfert thermionique-diffusif, et prévoit que la capture des charges mobiles s'effectue aux bords des grains. Cette théorie s'accorde parfaitement avec les caractéristiques expérimentales $I-V$ et nous permet de déterminer la valeur moyenne de la dimension des grains.
\end{abstract}

\begin{abstract}
The electrical properties of polycrystalline silicon resistors in the non-linear regime are examined. The adopted model is based on a thermionic-diffusion transport mechanism, and assumes charge trapping at the grain boundary. The theory closely fits experimental $I-V$ characteristics, and allows for the determination of the average grain size.
\end{abstract}

1. Introduction. - Polycrystalline silicon films have been widely investigated with regard to both their electrical and structural properties [1-4]. The film conductivity was measured vs several technological parameters, such as doping density, deposition rate and grain size, and comprehensive models of current transport in polycrystalline materials have been developed [5].

In this paper we investigate the electrical properties of polycrystalline silicon resistors in the non-linear regime, i.e. for large values of the applied fields. Experimentally-observed current-voltage characteristics are interpreted in terms of the grain-boundary trapping model. According to such a model, free carriers are trapped at the grain boundary, thus creating a charge sheet and a potential barrier opposing the transfer of carriers from a grain to the neighbouring ones. The energy-band spatial distribution, illustrated in figure 1 , is similar to that of a chain of Schottky-barrier diodes connected back to back, with a vanishingly-thin metal film. The theory is developed on the assumption of a dominant thermionic-diffusion mechanism, and found to closely fit experimental data at room and higher temperatures. The voltage partition between forward- and reverse-biased depletion layers is examined in the next Section. Thermionic and thermionic-diffusion theories are developed in section 3 and 4 . Section 5 is devoted to the analysis of the barrier height and section 6 to the description of the experiments. Final conclusions are drawn in section 7 .

(*) Work supported by CNR, Lamel Laboratory, Bologna, Italy.
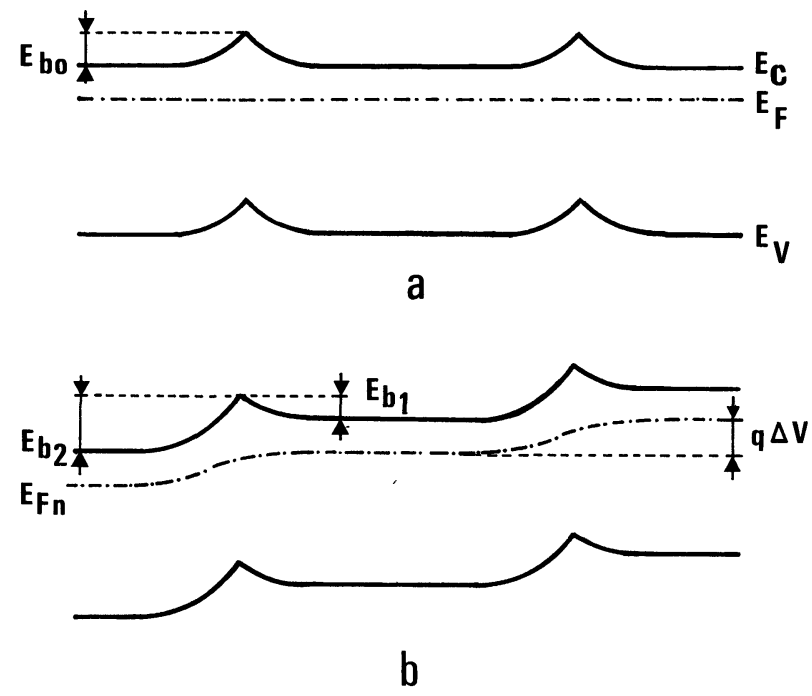

FIG. 1. - Sketch of the band diagram in polycrystalline silicon films. (a) Equilibrium, (b) Non-equilibrium.

2. Partition of the applied voltage. - With reference to an $\mathrm{n}$-doped polycrystalline material, we assume the one-dimensional geometry illustrated in figure $1 a$, and restrict ourselves to the consideration of partially-depleted crystallites. By denoting with $Q_{\mathrm{t}}$ the charge per unit area trapped at the grain boundary, the space charge $Q_{\mathrm{s} 0}$ at each side of the grain boundary is given in equilibrium by

$$
Q_{\text {s } 0}=-Q_{\mathrm{t}} / 2
$$

and the corresponding height of the energy barrier is

$$
E_{\mathrm{b} 0}=k T+Q_{\mathrm{s} 0}^{2} /\left(2 i_{\mathrm{s}} N_{\mathrm{D}}\right)
$$


as results from Poisson's equation. In (2) $\varepsilon_{\mathrm{s}}$ and $N_{\mathrm{D}}$ represent the semiconductor dielectric constant and the impurity concentration, respectively.

If a voltage $\Delta V$ is applied between two adjacent grains, the band configuration is modified as shown in figure $1 b$ : carriers crossing the grain boundary from the two sides experience now different barrier heights $E_{\mathrm{b} 1}$ and $E_{\mathrm{b} 2}$, such that

$$
\Delta V=\left(E_{\mathrm{b} 2}-E_{\mathrm{b} 1}\right) / q .
$$

Due to charge neutrality, the following condition holds

$$
Q_{\mathrm{s} 1}+Q_{\mathrm{s} 2}=-Q_{\mathrm{t}}
$$

$Q_{\mathrm{s} 1}$ and $Q_{\mathrm{s} 2}$ representing the space charges at the two sides of the grain boundary. It has to be observed, however, that $Q_{\mathrm{t}}$ may be affected by the applied voltage $\Delta V$. From eq. (2) we have

$$
\begin{aligned}
E_{\mathrm{b} 1} & =k T+Q_{\mathrm{s} 1}^{2} /\left(2 \varepsilon_{\mathrm{s}} N_{\mathrm{D}}\right) \\
& =k T+\left(Q_{\mathrm{s} 0}^{\prime}-\Delta Q_{\mathrm{s}}\right)^{2} /\left(2 \varepsilon_{\mathrm{s}} N_{\mathrm{D}}\right) \\
E_{\mathrm{b} 2} & =k T+Q_{\mathrm{s} 2}^{2} /\left(2 \varepsilon_{\mathrm{s}} N_{\mathrm{D}}\right) \\
& =k T+\left(Q_{\mathrm{s} 0}^{\prime}+\Delta Q_{\mathrm{s}}\right)^{2} /\left(2 \varepsilon_{\mathrm{s}} N_{\mathrm{D}}\right)
\end{aligned}
$$

where

$$
\begin{aligned}
Q_{\mathrm{s} 0}^{\prime} & =\left(Q_{\mathrm{s} 1}+Q_{\mathrm{s} 2}\right) / 2 \\
\Delta Q_{\mathrm{s}} & =\left(Q_{\mathrm{s} 2}-Q_{\mathrm{s} 1}\right) / 2
\end{aligned}
$$

and, taking account of (3),

$$
\Delta Q_{\mathrm{s}}=q \varepsilon_{\mathrm{s}} N_{\mathrm{D}} \Delta V /\left(2 Q_{\mathrm{s} 0}^{\prime}\right) .
$$

From eqs. (5) and (7), we finally obtain

$$
\begin{aligned}
& E_{\mathrm{b} 1}=E_{\mathrm{b} 0}^{\prime}-q \Delta V / 2+q^{2} \varepsilon_{\mathrm{s}} N_{\mathrm{D}}(\Delta V)^{2} /\left(8 Q_{\mathrm{s} 0}^{\prime 2}\right) \\
& E_{\mathrm{b} 2}=E_{\mathrm{b} 0}^{\prime}+q \Delta V / 2+q^{2} \varepsilon_{\mathrm{s}} N_{\mathrm{D}}(\Delta V)^{2} /\left(8 Q_{\mathrm{s} 0}^{\prime 2}\right)
\end{aligned}
$$

having defined

$$
E_{\mathrm{b} 0}^{\prime}=k T+Q_{\mathrm{s} 0}^{\prime 2} /\left(2 \varepsilon_{\mathrm{s}} N_{\mathrm{D}}\right) .
$$

Eqs. (8) show that the potential drop between two adjacent grains is non-uniformly distributed between the two space-charge regions. This is due to the nonlinear relationship between the space charge and the barrier height, as appears from eqs. (5).

If the trapped charge $Q_{\mathrm{t}}$ is not appreciably influenced by the application of the voltage $\Delta V, E_{\mathrm{b} 0}^{\prime}$ negligibly differs from $E_{\mathrm{b} 0}$. This is indeed the case if the band bending at the grain boundary is not too large, and if the trapping states are nearly monovalent and located at midgap, as recently demonstrated [6]. In this case, the following condition must be fulfilled

$$
E_{\mathrm{b} 0}<k T \ln \left(N_{\mathrm{D}} / n_{\mathrm{i}}\right)
$$

in order to assure that the trapping states are completely filled in equilibrium and, a fortiori, in nonequilibrium-conditions.
3. Thermionic theory. - According to Seto's model [5], the dominant transport mechanism in polycrystalline silicon films is thermionic emission over the barriers. The current density flowing from one grain to the next is thus given by

$$
\begin{aligned}
J=A^{*} & T^{2} \exp \left[-\left(E_{\mathrm{c}}-E_{\mathrm{F}}\right) / k T\right] \times \\
& \times\left[\exp \left(-E_{\mathrm{b} 1} / k T\right)-\exp \left(-E_{\mathrm{b} 2} / k T\right)\right]
\end{aligned}
$$

where $A^{*}$ is the Richardson constant, $E_{\mathrm{c}}$ and $E_{\mathrm{F}}$ are the bottom energy of the conduction band and the Fermi level, respectively, in the neutral region.

Taking account of eqs. (8) and (9), the current density becomes

$J=2 q n_{0} v_{\mathrm{c}} \exp \left[-E_{\mathrm{b} 0}^{\prime} / k T-\right.$

$\left.-q^{2}(\Delta V)^{2} / 16 k T\left(E_{\mathrm{b} 0}^{\prime}-k T\right)\right] \sinh (q \Delta V / 2 k T)$

where $n_{0}$ is the electron concentration within the neutral region of the crystallites, and

$$
v_{\mathrm{c}}=\left(k T / 2 \pi m^{*}\right)^{1 / 2}
$$

is the collection velocity defined by Crowell and Sze [7].

The current-voltage characteristic of a polycrystalline silicon resistor having section $S$ and length $g L$ ( $L$ being the average length of a single crystallite) is thus given by

$I=2 S J_{\mathrm{TH}} \exp \left[-E_{\mathrm{b} 0}^{\prime} / k T-\right.$

$\left.-(q V)^{2} / 16 g^{2} k T\left(E_{\mathrm{b} 0}^{\prime}-k T\right)\right] \sinh (q V / 2 g k T)$

where $V=g \Delta V$ represents the applied voltage, and $J_{\mathrm{TH}}=q n_{0} v_{\mathrm{c}}$. As expected from symmetry considerations, $I$ is an odd function of the applied voltage $V$.

4. Thermionic-diffusion theory. - From the shape of the potential barriers illustrated in figure 1, it appears that electrons crossing the grain boundary experience a sudden variation of the electric field. A Monte Carlo simulation of a similar process, namely the injection of carriers from the base into the collector space-charge region of a bipolar transistor [8], has revealed that the electron distribution function at the boundary between the two regions becomes nearly hemimaxwellian. A similar situation is likely to occur at the grain boundary, provided the potential drop between two adjacent grains exceeds $k T / q$. The transport process, on the other hand, is governed by drift-diffusion over most of the spacecharge region, except in a thin layer of a thickness comparable to the carrier mean-free path, and centered around the grain boundary. Consequently, a thermionic-diffusion theory appears more suitable than a pure thermionic theory to describe the transport process in polycrystalline materials.

A straightforward application of the T-D theory to the case under consideration, leads to the following expression of the current density

$J=2 J_{\mathrm{TD}} \exp \left[-E_{\mathrm{b} 0}^{\prime} / k T-\right.$

$\left.-(q \Delta V)^{2} / 16 k T\left(E_{\mathrm{b} 0}^{\prime}-k T\right)\right] \sinh (q \Delta V / 2 k T)$ 
having defined

$$
J_{\mathrm{TD}}=\frac{q n_{0} v_{\mathrm{c}}}{1+v_{\mathrm{c}}\left(D_{1}+D_{2}\right) / v_{\mathrm{D}}} .
$$

In (15) $v_{\mathrm{D}}=\mu_{\mathrm{n}} k T / q L_{\mathrm{D}}$ is the Debye velocity, $L_{\mathrm{D}}=\left(2 \varepsilon_{\mathrm{s}} k T / q^{2} n_{0}\right)^{1 / 2}$ the Debye length, and

$$
D_{1}=D\left(\sqrt{\left.E_{\mathrm{b} 1} / k T\right)}, \quad D_{2}=D\left(\sqrt{E_{\mathrm{b} 2} / k T}\right)\right.
$$

represent the Dawson function.

The current-voltage characteristic of a polycrystalline silicon resistor is thus given by

$$
\begin{aligned}
& I=2 S J_{\mathrm{TD}} \exp \left[-E_{\mathrm{b} 0}^{\prime} / k T-\right. \\
& \left.-(q V)^{2} / 16 g^{2} k T\left(E_{\mathrm{b} 0}^{\prime}-k T\right)\right] \sinh (q V / 2 g k T)
\end{aligned}
$$

differing from eq. (13) due to the preexponential factor, which slightly depends on the applied voltage. $J_{\mathrm{TD}}$ is plotted in figure $2 v s$ the impurity concentration at different temperatures : the temperature dependence of $J_{\mathrm{TD}}$ is shown to be very weak, and therefore negligible in most practical considerations.

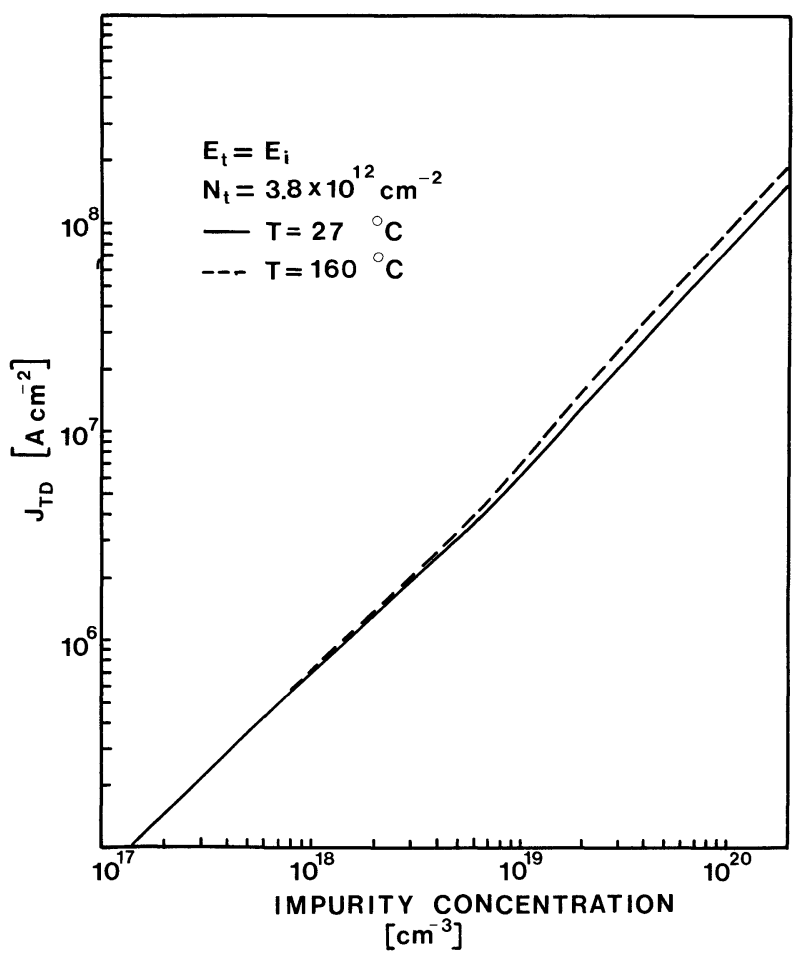

Fig. 2. - Plot of $J_{\mathrm{TD}} v s$ impurity concentration at different temperatures.

5. Barrier height. - The barrier height $E_{\mathrm{b} 0}$ is a function of both the impurity concentration $N_{\mathrm{D}}$ and the charge trapped at the grain boundary $Q_{\mathrm{t}}$. The latter, in turn, depends on the energy level of the trapping states $E_{\mathrm{t}}$ according to Shockley-Read statistics

$$
Q_{\mathrm{t}}=-q N_{\mathrm{t}}\left[1+\frac{1}{2} \exp \left(E_{\mathrm{t}}+E_{\mathrm{b} 0}-E_{\mathrm{F}}\right) / k T\right]^{-1}
$$

where $E_{\mathrm{t}}$ and $E_{\mathrm{F}}$ are referred to the intrinsic Fermi level in the neutral region of the crystallites. From eqs. (1) and (2) $Q_{t}$ may also be expressed as

$$
Q_{\mathrm{t}}=-\left[8 \varepsilon_{\mathrm{s}} N_{\mathrm{D}}\left(E_{\mathrm{b} 0}-k T\right)\right]^{1 / 2}
$$

and, by equating the terms on the right of (17) and (18), the following equation if obtained

$$
E_{\mathrm{b} 0}=E_{\mathrm{F}}-E_{\mathrm{t}}+k T \ln \left\{2\left[q N_{\mathrm{t}} /\left(8 \varepsilon_{\mathrm{s}} N_{\mathrm{D}}\left(E_{\mathrm{b} 0}-k T\right)\right)-1\right]\right\}
$$

which allows to determine $E_{\mathrm{b} 0}$ making use of an iterative procedure. The barrier height is represented versus the impurity concentration at different temperatures in figure 3 . We distinguish two situations

$$
E_{\mathrm{b} 0} \cong k T+q^{2} N_{\mathrm{t}}^{2} /\left(8 \varepsilon_{\mathrm{s}} N_{\mathrm{D}}\right)
$$

for $E_{\mathrm{F}}-E_{\mathrm{t}}-E_{\mathrm{b} 0} \gg k T$, and

$$
\begin{aligned}
& E_{\mathrm{b} 0} \cong E_{\mathrm{G}} / 2-E_{\mathrm{t}}+ \\
& \quad+k T \ln \left\{q N_{\mathrm{D}}^{1 / 2} N_{\mathrm{t}} / N_{\mathrm{c}}\left[2 \varepsilon_{\mathrm{s}}\left(E_{\mathrm{b} 0}-k T\right)\right]^{1 / 2}\right\}
\end{aligned}
$$

for $E_{\mathrm{t}}+E_{\mathrm{b} 0}-E_{\mathrm{F}} \gg k T$, which correspond to the regions of larger and smaller impurity concentrations, respectively. In the former situation all the trapping states are filled; $Q_{\mathrm{t}}=q N_{\mathrm{t}}$, and $E_{\mathrm{b} 0}$ depends on temperature through the term $k T$. The barrier height is therefore a slowly increasing function of temperature. In the latter case, most trapping states are empty : the argument of the logarithm in $(20 b)$ is smaller than 1 at the lowest impurity concentrations, and $E_{\mathrm{b} 0}$ is decreasing with temperature, as shown in figure 3 .

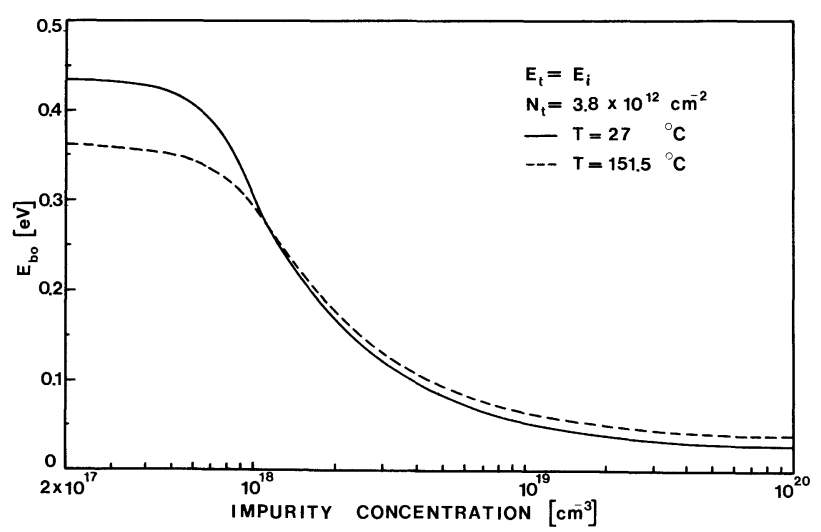

Fig. 3. - Plot of the barrier height $v s$ impurity concentration at different temperatures.

6. Experiments. - Ion implanted, polycrystalline silicon resistors were manufactured by a standard silicon-gate process, and their $I-V$ characteristics measured at various temperatures. Two implantation doses have been employed $\left(\varnothing_{1}=5.3 \times 10^{13} \mathrm{~cm}^{-2}\right.$ and $\varnothing_{2}=2.1 \times 10^{13} \mathrm{~cm}^{-2}$ ) and two resistor nomi- 
nal lengths have been adopted $\left(L_{1}=26 \mu \mathrm{m}\right.$ and $L_{2}=14 \mu \mathrm{m}$ ) in our experiments, whereas the resistor width has been kept constant, and equal to $6 \mu \mathrm{m}$. A systematic resistance ratio about equal to three was observed between the resistors of different length. Assuming a resistance proportional to the effective resistor length, a lateral diffusion of the dopant at the ohmic contacts is inferred of about $4 \mu \mathrm{m}$. As a consequence, the effective resistor lengths turn out to be $18 \mu \mathrm{m}$ and $6 \mu \mathrm{m}$, respectively.

In accordance with previous determinations [5, 6], the film conductivity turned out to be thermally activated, with activation energies $E_{\mathrm{a}}=0.07 \mathrm{eV}$ and $0.17 \mathrm{eV}$ for the two implantation doses.

Figure 4 shows typical $I-V$ characteristics of the most heavily implanted resistors of nominal length $L_{1}=26 \mu \mathrm{m}$. Experimental data were fit at each temperature with eq. (16) by adjusting three parameters : barrier height, average number of crystallites in series within the resistor, and preexponential factor. Both $E_{\mathrm{b} 0}^{\prime}$ and $J_{\mathrm{TD}}$ have been treated as voltageindependent parameters, and the agreement between theory and experiment is satisfactory. As expected, the obtained values of $g$ are independent of temperature and about equal to 100 , indicating an average grain size of $180 \mathrm{~nm}$. Instead, $E_{\mathrm{b} 0}^{\prime}$ is found two-three times larger than expected from the activation-energy

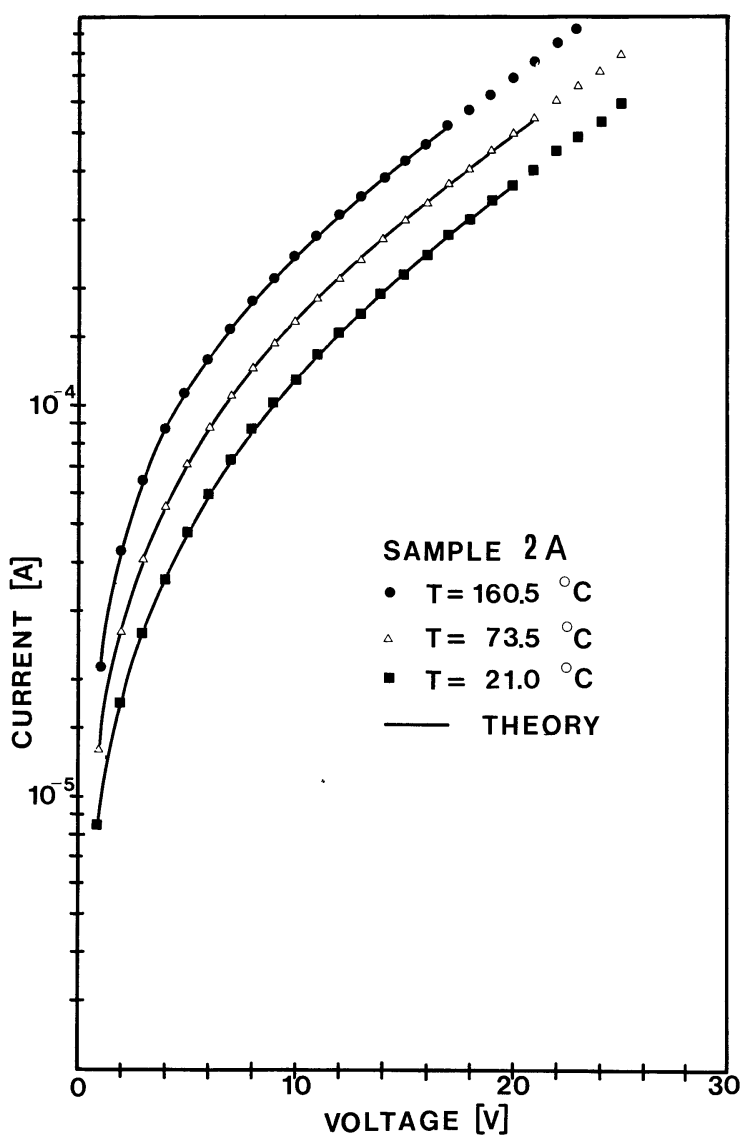

FIG. 4. $-I-V$ characteristics of a polycrystalline silicon resistor at various temperatures. Implantation dose $\varnothing=5.3 \times 10^{13} \mathrm{~cm}^{-2}$; resistor niminal length $L=26 \mu \mathrm{m}$; resistor width $W=6 \mu \mathrm{m}$. measurements, and increasing with temperature. As a consequence, also $J_{\mathrm{TD}}$ increases with temperature in an unpredictable manner.

The $I-V$ characteristics of a smaller-length resistor are shown in figure 5 . The agreement between theory and experiment is worse in this case, especially in the high-field region, where an increase of current is observed, probably due to impact ionisation. The average field becomes about $4 \div 5 \times 10^{4} \mathrm{~V} \mathrm{~cm}^{-1}$ at the largest applied voltages, while the local field can be an order of magnitude larger, substantiating the above hypothesis.

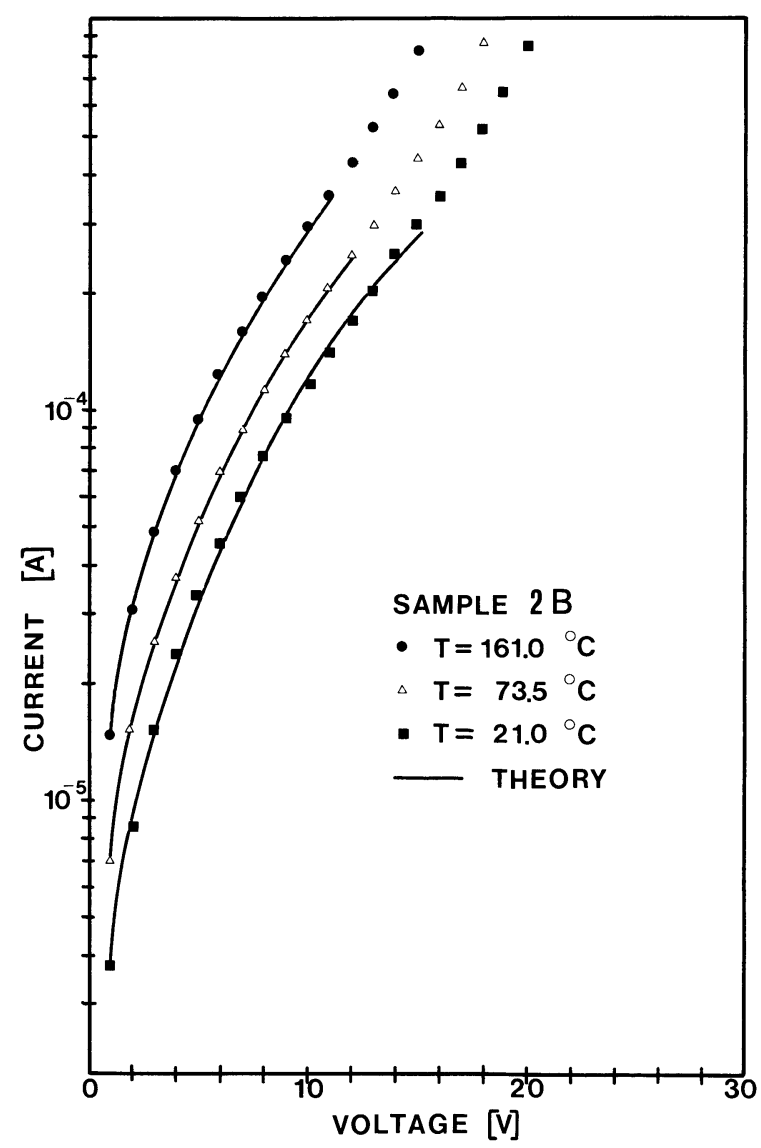

FIG. 5. $-I-V$ characteristics of a polycrystalline silicon resistor at various temperatures. Implantation dose $\varnothing=5.3 \times 10^{13} \mathrm{~cm}^{-2}$; resistor nominal length $L=14 \mu \mathrm{m}$; resistor width $W=6 \mu \mathrm{m}$.

Similar features exhibit the $I-V$ characteristics of the lightly doped resistors, shown in figures 6 and 7 . In this case, the obtained values of the barrier height are in closer agreement with the measured activation energy, ranging from 0.16 to $0.19 \mathrm{~V}$ compared with $0.17 \mathrm{eV}$.

Results of the complete set of measurements are reported in table I.

7. Summary and conclusion. - The transport properties of polycrystalline silicon resistors in the non-linear regime have been examined making use of the grain-boundary trapping model. The assumed 


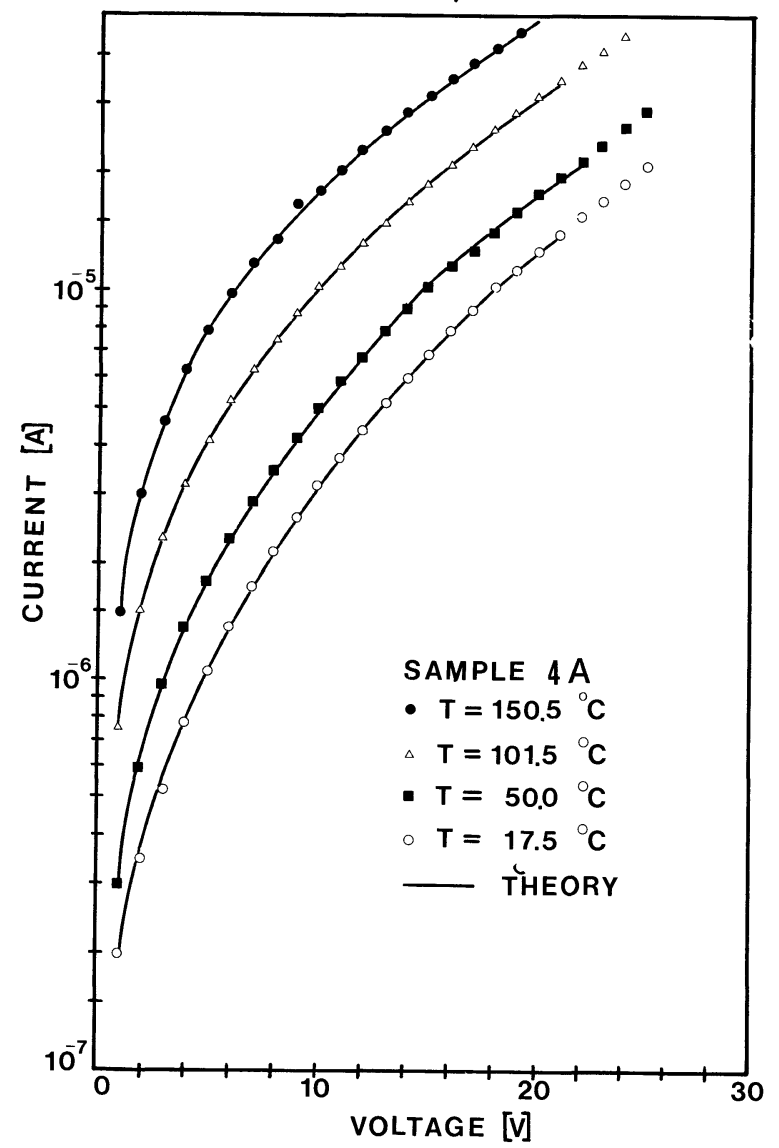

FIG. 6. - I- $V$ characteristics of a polycrystalline silicon resistor at various temperatures. Implantation dose $\varnothing=2.1 \times 10^{13} \mathrm{~cm}^{-2}$; resistor nominal length $L=26 \mu \mathrm{m}$; resistor width $W=6 \mu \mathrm{m}$.

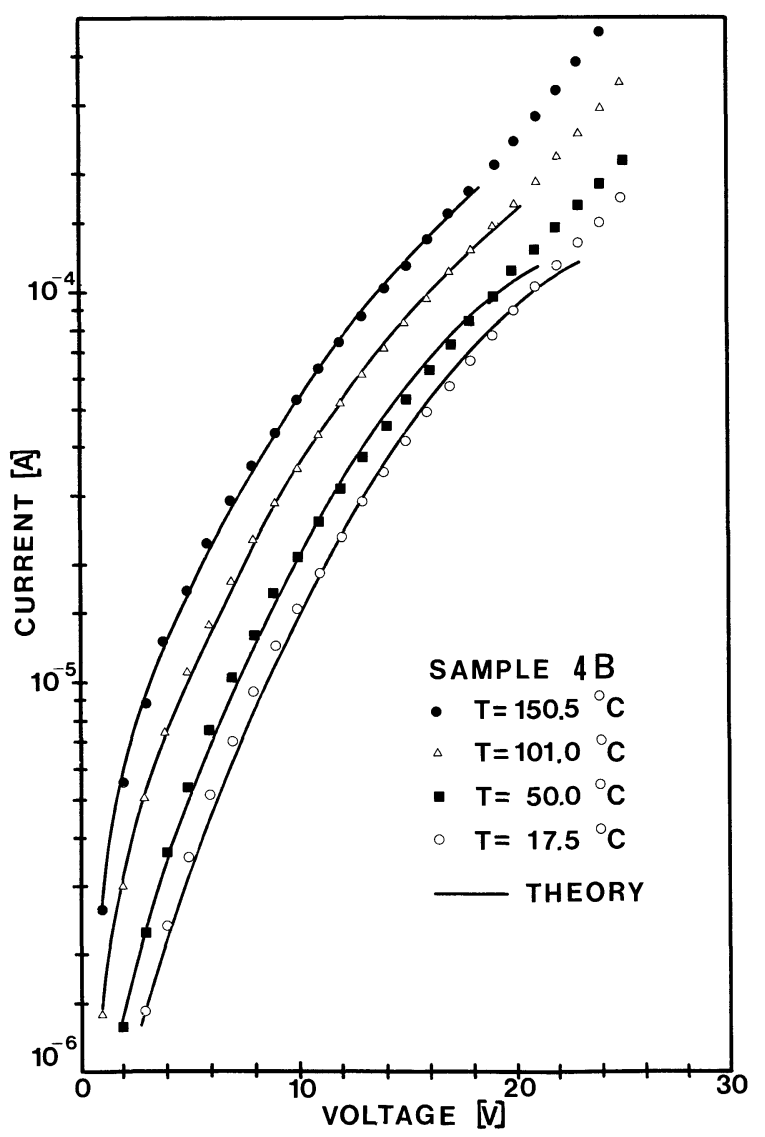

TABLE I $(*)$

List of the fitting parameters $g, E_{\mathrm{b} 0}^{\prime}$, and $J_{\mathrm{TD}}$

\begin{tabular}{lrrcc}
\multicolumn{1}{c}{ Sample } & \multicolumn{1}{c}{$T\left({ }^{\circ} \mathrm{C}\right)$} & \multicolumn{1}{c}{$g$} & $E_{\mathrm{b} 0}^{\prime}(\mathrm{eV})$ & \multicolumn{1}{c}{$J_{\mathrm{TD}}\left(\mathrm{A} \mathrm{cm}^{-2}\right)$} \\
$S 1 \mathrm{~A}$ & - & \multicolumn{1}{c}{-} & - & - \\
$\varnothing=5.3 \times 10^{13}$ & 160.0 & 103 & 0.19 & $7.02 \times 10^{5}$ \\
& 80.5 & 95 & 0.13 & $1.46 \times 10^{5}$ \\
$S 1 \mathrm{~B}$ & 21.0 & 100 & 0.11 & $1.03 \times 10^{5}$ \\
$\varnothing=5.3 \times 10^{13}$ & 160.0 & 38 & 0.20 & $3.33 \times 10^{5}$ \\
& 80.5 & 38 & 0.15 & $1.08 \times 10^{5}$ \\
$S 2 \mathrm{~A}$ & 21.0 & 39 & 0.13 & $6.89 \times 10^{4}$ \\
$\varnothing=5.3 \times 10^{13}$ & 161.0 & & not convergent \\
& 73.5 & 106 & 0.14 & $1.73 \times 10^{5}$ \\
$S 2 \mathrm{~B}$ & 21.0 & 102 & 0.11 & $8.29 \times 10^{4}$ \\
$\varnothing=5.3 \times 10^{23}$ & 160.5 & 40 & 0.18 & $1.00 \times 10^{5}$ \\
& 73.5 & 41 & 0.14 & $4.56 \times 10^{4}$ \\
$S 3 \mathrm{~A}$ & 21.0 & 47 & 0.13 & $4.53 \times 10^{4}$ \\
$\varnothing=2.1 \times 10^{13}$ & 151.5 & 84 & 0.16 & $2.40 \times 10^{4}$ \\
& 70.5 & 80 & 0.14 & $1.01 \times 10^{4}$ \\
$S 3 \mathrm{~B}$ & 24.5 & 73 & 0.13 & $5.21 \times 10^{3}$ \\
$\varnothing=2.1 \times 10^{13}$ & 152.5 & 45 & 0.19 & $6.75 \times 10^{4}$ \\
& 53.0 & 44 & 0.16 & $2.66 \times 10^{4}$ \\
$S 4 \mathrm{~A}$ & 24.5 & 48 & 0.16 & $3.53 \times 10^{4}$ \\
$\varnothing=2.1 \times 10^{13}$ & 150.5 & 93 & 0.16 & $1.53 \times 10^{4}$ \\
& 101.5 & 82 & 0.14 & $7.08 \times 10^{3}$ \\
& 50.0 & 74 & 0.14 & $3.43 \times 10^{3}$ \\
$S 4 \mathrm{~B}$ & 17.5 & 75 & 0.13 & $2.48 \times 10^{3}$ \\
$\varnothing=2.1 \times 10^{13}$ & 150.5 & 47 & 0.19 & $3.60 \times 10^{4}$ \\
& 101.5 & 47 & 0.18 & $2.67 \times 10^{4}$ \\
& 50.0 & 46 & 0.17 & $1.69 \times 10^{4}$ \\
& 17.5 & 49 & 0.17 & $1.58 \times 10^{4}$
\end{tabular}

(*) A denotes the resistor nominal length $L=26 \mu \mathrm{m}$. B denotes the resistor nominal length $L=14 \mu \mathrm{m}$

transport mechanism is thermionic emission over the barriers at the grain boundary, and drift-diffusion within the crystallites, leading to a thermionicdiffusion theory similar to that developed for Schottkybarrier diodes [7]. The resulting $I-V$ characteristic is an odd function of the applied voltage, as expected from symmetry considerations, and fits quite well experimental data at room and higher temperatures.

Thermionic-field emission also was considered as a possible transport mechanism due to the apparent temperature-increase of the barrier height. In this case, however, the conductivity activation energy should exhibit a similar behaviour, which was not observed in our experiments.

The fitting procedure does not allow to exploit all the informative content of the non-linear $I-V$ characteristics, probably due to impact ionisation effects which are not included in the present model. It has to be observed that, while the average number of crystallites in series within the resistor is related to the slope of the $I-V$ characteristic in the semilog plot, the barrier height is derived from the curvature of the same characteristic, which can be strongly affected by

FIG. 7. - I- $V$ characteristics of a polycrystalline silicon resistor at various temperature. Implantation dose $\varnothing=2.1 \times 10^{13} \mathrm{~cm}^{-2}$; resistor nominal length $L=14 \mu \mathrm{m}$; resistor width $W=6 \mu \mathrm{m}$. 
impact ionisation effects. In turn, such an incorrect determination of the barrier height produces even stronger effects on the preexponential factor $J_{\mathrm{TD}}$, preventing from an exact evaluation of the electricallyactive impurity concentration. The present model, while correctly predicting the $I-V$ characteristic of polycrystalline silicon resistors, seems therefore scarcely suitable for determining the physical parameters of interest, with the only possible exception of the grain size.

\section{References}

[1] Cower, M. E. and Sedgwick, T. O., J. Electrochem. Soc. 119 (1972) 1565.

[2] Fripp, A. L., J. Appl. Phys. 46 (1975) 1240.

[3] Kamins, T. I., IEEE Trans. Parts, Hybrids and Packaging VHP-10 (1974) 221.

[4] SETo, J. Y. W., J. Electrochem. Soc. 122 (1975) 1240.

[5] Seto, J. Y. W., J. Appl. Phys. 46 (1975) 5247.
[6] Baccarani, G., Riccò, B. and Spadini, G., J. Appl. Phys. (To be published).

[7] Crowell, C. R. and Sze, S. M., Solid-State Electron. Devices 9 (1966) 1035.

[8] Baccarani, G., Jacoboni, C. and Mazzone, A. M., SolidState Electron. Devices 20 (1977) 5. 